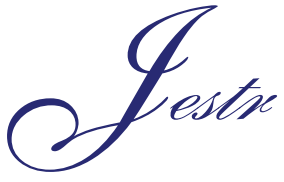

Journal of Engineering Science and Technology Review 3 (1) (2010) 23-26

Research Article
JOURNAL OF

Engineering Science and

Technology Review

www.jestr.org

\title{
Investigation of Wetland Soil Properties affecting Optimum Soil Cultivation
}

\author{
K.A. Adeniran* and O.O. Babatunde \\ Department of Agricultural and Biosystems Engineeringv,University of Ilorin, P.M.B. 1515,Ilorin. Kwara State. Nigeria.
}

Received 19 March 2009; Accepted 29 January 2010

\begin{abstract}
An investigation was carried out on wetland (fadama) soil properties affecting optimum soil cultivation. A cone penetrometer and a shear vane apparatus $(19 \mathrm{~mm})$ were used to determine the cone index and the torque that cause the soil to shear at different moisture contents. The study shows that the cone index and shear vane of fadama soils increased with depth and decreased with increase in moisture content. High moisture content reduced the soil cohesion. The internal frictional angle of the soil was $37.9^{0}$. The following values were obtained for soil cohesion $112 \mathrm{kN} / \mathrm{m}^{2}, 62 \mathrm{kN} / \mathrm{m}^{2}, 38 \mathrm{kN} / \mathrm{m}^{2}, 30 \mathrm{kN} / \mathrm{m}^{2}$, and $12 \mathrm{kN} / \mathrm{m}^{2}$ at moisture contents of $0 \%, 5 \%, 10 \%, 15 \%$ and $20 \%$ respectively. Moisture content between $10 \%-15 \%$ (dry basis) appeared ideal for cultivation of the soil. For this soil the critical moisture content was found to be $23.72 \%$. Moisture content beyond the critical level needs to be drained before cultivation is carried out.
\end{abstract}

Keywords: Wetland, fadama, moisture content, cone index, shear vane, shear torque, internal frictional angle, soil cohesion.

\section{Introduction}

Wetlands (fadamas) are seasonally flooded low lying lands occurring along water courses, or on valley bottoms and which usually have high water table. Tiner (1999) reported that wetlands are flooded or saturated for varying periods of time during the year. Traction problem on wetland soil have been a major limitation to the adaptation of mechanization practice for cultivating the land. Mijindadi et al., (1993) reported that data sourced from Water Resources Consultants of the Agricultural Development Projects (ADP) show that about 3.5 million hectares of Nigeria's landmass are fadama lands out of which only 2 million hectares can be put under small-scale irrigation. The development of effective planning and practice of the fadama field will enhance the production of such crops like rice, vegetative products (tomatoes, pepper and others) thereby making planting season available for more than one time in a year (dry season), leading to increase in food production. Gee-Clough et al., (1993) reported that this is a major concern in most Asian countries where rice is one of the major cultivated crops. Hanselman and Noll (2003) reported that little work has been published on natural variability of wetland soils. In Nigeria, there is scarcity of data on mechanical and physical properties of fadama soils and their critical moisture contents for tillage purposes. In Nigeria, data are scarce on mechanical and physical properties of fadama soils and their critical moisture contents for tillage. These data are needed for evaluating changes in these soils over time. This paper determines soil parameters such as shear stress, normal stress, soil cohesion, and moisture content affecting the sinkage of agricultural machinery on fadama fields.

\section{Materials and Method}

\subsection{Study Site}

The study was carried out at the fadama field (Nursery unit) of the National Centre for Agricultural Mechanization (NCAM) Idofian, Kwara State. Idofian lies between latitude $8^{\circ} 26 \mathrm{~W}$ and longitude $4^{0} 30^{\prime} \mathrm{E}$. The field was mainly used for planting melon, rice, and vegetables. The place also serves as nursery unit for transplanting crops due to its high moisture content and fertility.

\subsection{Cone Penetrometer Resistance}

A cone penetrometer was used to determine the degree of soil compaction resulting from the application of different tillage operations. The cone penetrometer consists of the force measuring components, the depth-measuring component and the conical tip for penetration into the soil when force is been applied. The force applied is directly read on the chart at the top of the instrument while the depth measurement is preceded by the relative movement of the footplate shaft and penetrometer tip as the tip is forced into the soil.

\footnotetext{
* E-mail address: kadeniran_20003@yahoo.com

ISSN: 1791-2377 (C) 2010 Kavala Institute of Technology. All rights reserved.
} 


\subsection{Determination of Soil Shear Vane}

The shear vane apparatus (Fig.1) consists of a stainless steel vane of four thin rectangular blades, carried on the end of a high tensile steel rod. A sleeve packed with grease encloses the rod. The vane and rod are pushed into the soil at a desire depth into the soil and torque is hereby applied at the top by hand rotation. The torque application continues until the soil shear and the value of the torque is read directly at the top of the shear vane. This procedure is repeated at various depths.

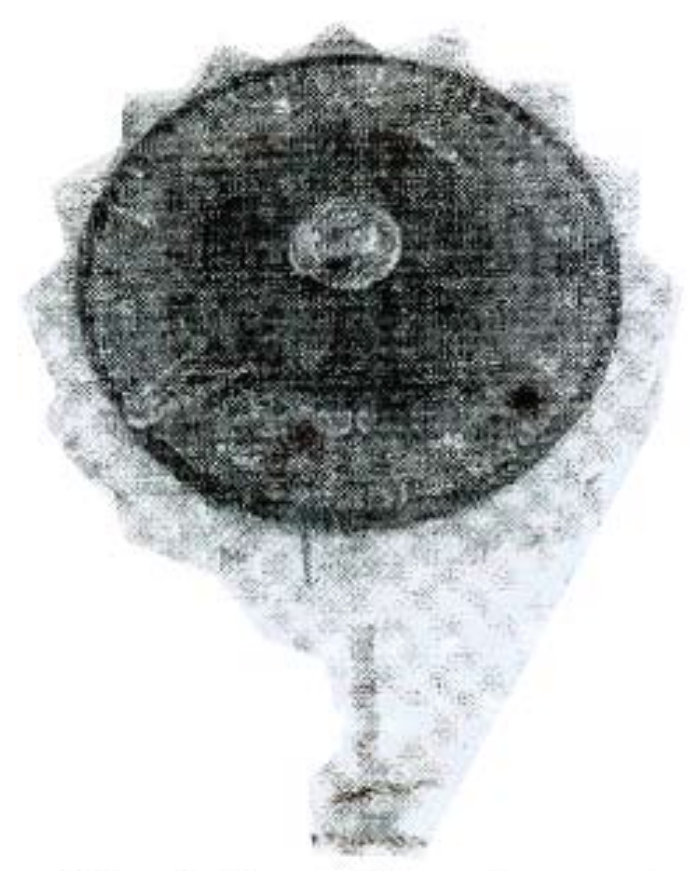

Figure 1. Shear Vane Apparatus.

\subsection{Shear Stress Measurements}

The direct shear box was used to determine the shear strength of soil samples taken from the fadama field. The specimen was confined in the shear box (Fig. 2) consisting of a square split horizontally at mid-height into two equal halves with a small clearance in-between the two halves. Porous plates were placed below and on top of the specimen when it was fully saturated or partially saturated to allow for free drainage. The porous plates were grooved to prevent slippage. A vertical force $(\mathrm{N})$ was applied to the specimen through a loading plate and shear stress is gradually applied on a

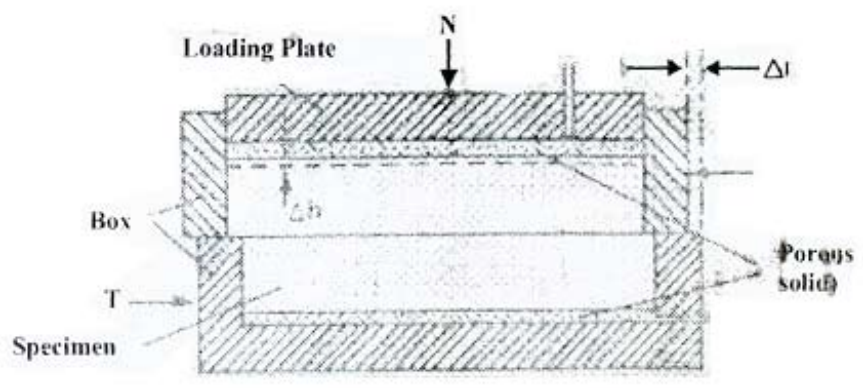

Figure 2. Direct Shear Apparatus. horizontal plane causing the two halves of the box to move relative to each other, the shear force $(\mathrm{T})$ was measured together with the corresponding shear displacement $(\Delta \mathrm{l})$. The change in thickness $(\Delta \mathrm{h})$ of the fadama soil samples was also determined. The reaction of the soil samples under different vertical forces and value of the shear stress at the point of failure were determined at moisture contents of $16.75 \%, 19.71 \%, 23.72 \%$ and $31.87 \%$ respectively.

\subsection{Statistical Model}

A simple regression model proposed by Reece (1971) was used to represent the mathematical relationship between shear stress, cone penetrometer resistance, shear vane and direct shear stress at different moisture contents.

$$
\begin{aligned}
& \mathrm{F}_{\max }=\mathrm{AC}+\mathrm{W} \tan \varphi \\
& \text { dividing both sides by } \mathrm{A}, \\
& \tau=\mathrm{C}+\sigma \tan \varphi
\end{aligned}
$$

Where $\mathrm{F}_{\max }=$ Maximum tractive force $(\mathrm{N})$,

$\mathrm{A}=$ Area occupied by soil sample $\left(\mathrm{m}^{2}\right)$,

$\mathrm{C}=$ Soil cohesion force $\left(\mathrm{kN} / \mathrm{m}^{2}\right)$,

$\mathrm{W}=$ Applied load $(\mathrm{kN})$,

$\varphi=$ Angle of shearing resistance $\left({ }^{0}\right)$,

$\tau=$ Shear stress $\left(\mathrm{N} / \mathrm{m}^{2}\right)$,

$\sigma=$ Normal stress $\left(\mathrm{N} / \mathrm{m}^{2}\right)$.

\section{Results and Discussion}

Fig 3 shows the results obtained with the use of the cone penetrometer on the fadama soil samples. Fig 3 shows that the average cone index increases with soil depth for the moisture contents of $16.75 \%, 19.71 \%, 23.72 \%$ and $31.97 \%$. The reason is because the moisture content deceases as the depth increases for $5 \mathrm{~cm}, 10 \mathrm{~cm}$, $15 \mathrm{~cm}, 20 \mathrm{~cm}$ and $25 \mathrm{~cm}$ soil depths. As the soil depth increases the soil structure becomes more stable, thereby resisting the cone penetration. Fig 4 shows the variations obtained when shear vane apparatus was used for different soil depths. Fig 4 shows a progressive increase in average shear with increase in soil depth. The factor responsible for the increase in shear force is the same as the responsible for that of cone index that is decrease in soil moisture content leading to the increase in compaction. Fig 5 shows that the average shear stress is linearly related to average shear vane. Fig 5 shows that the cone index and the shear vane at the different depths depend primarily on the nature and particle arrangement of the soil. Figs 6 and 7 show that the estimated average cone index and shear vane decreases with increase in moisture content (dry basis) until the moisture content of $23.72 \%$ was reached. Beyond this moisture content, a further increase in moisture content increases lead to an increase in the cone index and shear vane respectively. This shows that the critical moisture content for this soil is $23.72 \%$. Moisture content range between $10 \%-15 \%$ (dry basis) is workable and trafficable for cultivation practice. Beyond the critical moisture con- 
tent, cultivation practice becomes tedious, leading to high slippage, sinkage of machinery and lost of trafficability. For efficient cultivation of soil, moisture content beyond the critical value needs to be drained before cultivation. In Table 1, the statistical regression analysis against each of cone index and shear vane was used to determine the computed moisture content. The data were used to plot Fig 8. Fig 8 shows that as moisture content increases, the cone index decreases, and Table 9 shows that shear stress and shear vane decreases with increase in moisture content. Two statistical regression models produced from Figures 8 and 9 stated as follows:

$$
\mathrm{Y}=39-0.36 \mathrm{X}_{\mathrm{ci}}
$$

For cone index, and

$$
\mathrm{Y}=28.38-0.17 \mathrm{X}_{\mathrm{sv}}
$$

\section{For shear vane.}

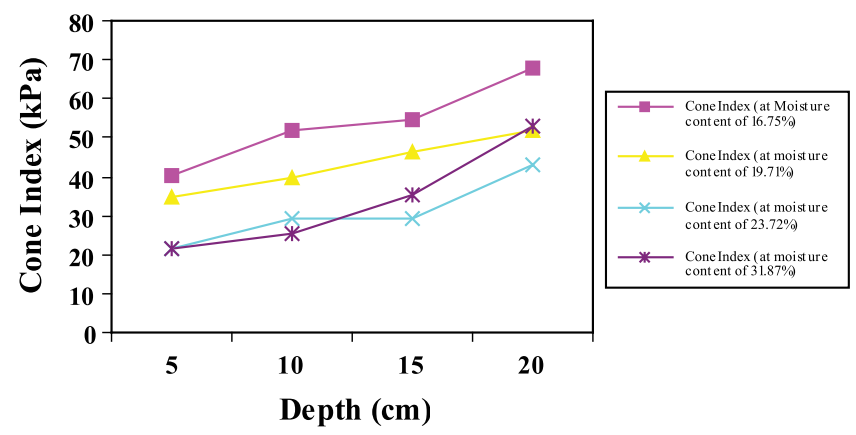

Figure 3. Effects of depth and moisture content on the cone index.

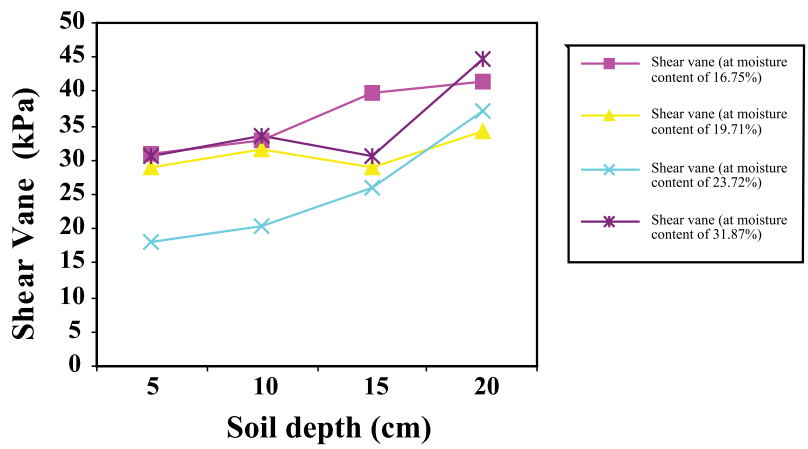

Figure 4. Effects of soil depth and moisture content on the shear vane of wetlands.

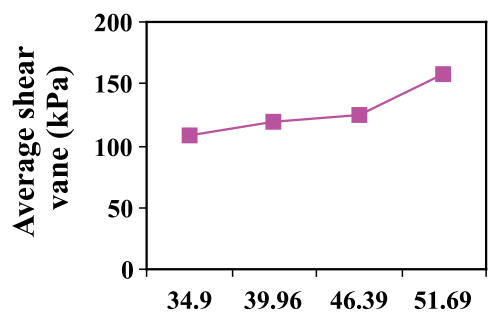

\section{Average cone index X $10000(\mathrm{kPa})$}

Figure 5. Relationship between average shear vane and average cone index.

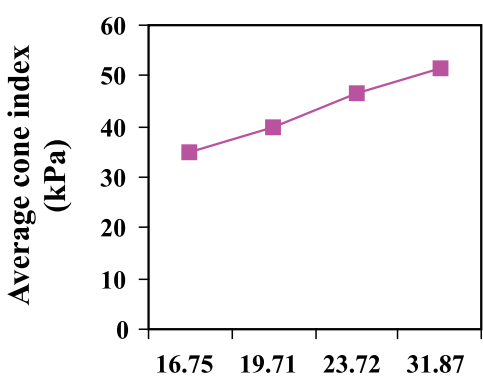

Moisture content (\%)

Figure 6. Relationship between average cone index and moisture content.

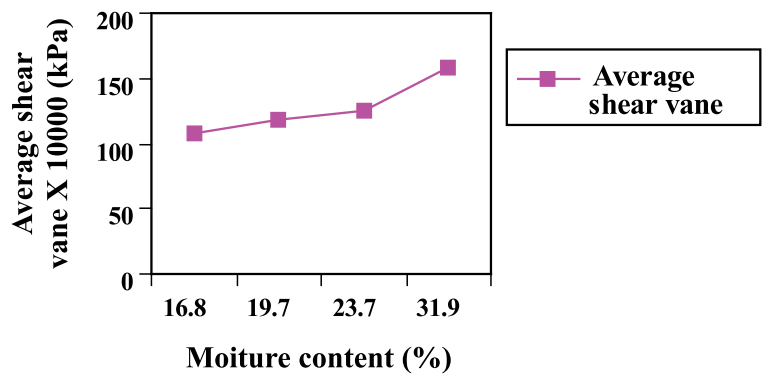

Figure 7. Relationship between average shear vane and moisture content

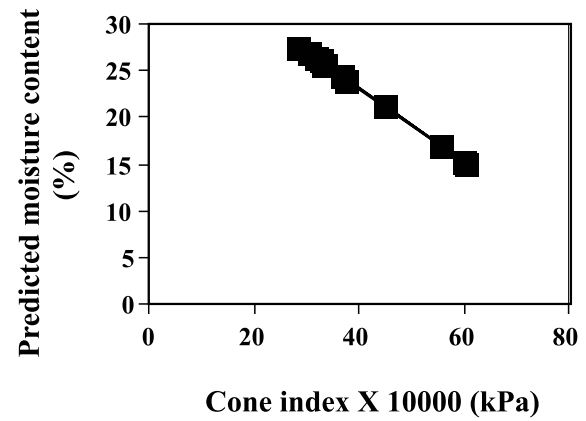

Figure 8. Using regression analysis of moisture content against cone index to predict the moisture content.

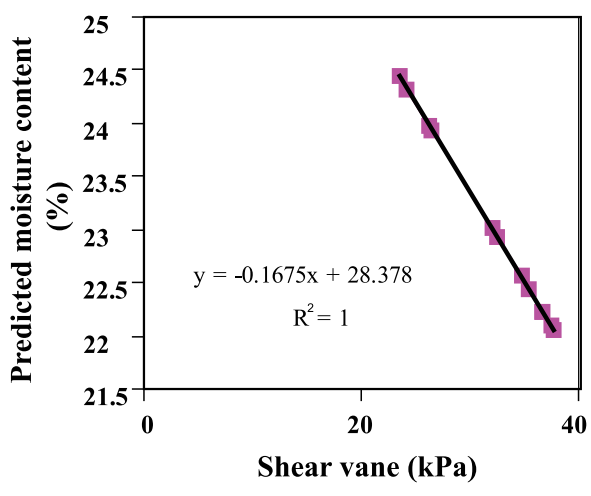

Figure 9. Relationship between the predicted moisture content and shear vane. 
Table 1. Statistical regression of field data of moisture content, cone index and shear vane

\begin{tabular}{|c|c|c|c|c|c|}
\hline \multirow{2}{*}{$\begin{array}{c}\text { Moisture } \\
\text { content } \\
(\%) Y\end{array}$} & \multicolumn{3}{|c|}{ Cone index x $10000(\mathrm{kPa})$} & \multirow{2}{*}{$\begin{array}{c}\text { Predicted } \\
\text { moisture } \\
- \text { content } \\
\mathbf{Y}_{\mathrm{CI}}(\%)\end{array}$} & \multirow{2}{*}{$\begin{array}{l}\text { Efficiency } \\
\text { Y/Y } \\
\quad(\%) \\
\quad \text { (\%) }\end{array}$} \\
\hline & $\mathbf{X}_{1}$ & $\mathbf{X}_{1} \mathbf{Y}$ & $\mathbf{X}_{1}{ }^{2}$ & & \\
\hline 22.60 & 33.07 & 747.38 & 1093.62 & 25.90 & 114.60 \\
\hline 24.84 & 28.07 & 718.38 & 837.52 & 27.53 & 110.83 \\
\hline 23.74 & 30.49 & 723.83 & 929.64 & 26.92 & 113.40 \\
\hline 18.03 & 59.77 & 1077.65 & 3572.45 & 15.33 & 85.02 \\
\hline 21.53 & 37.55 & 808.45 & 1410.00 & 24.12 & 112.03 \\
\hline 19.58 & 32.38 & 634.00 & 1048.46 & 26.17 & 133.66 \\
\hline 21.10 & 36.35 & 770.62 & 1321.32 & 24.60 & 116.59 \\
\hline 46.80 & 31.70 & 1483.56 & 1004.89 & 26.44 & 56.50 \\
\hline 27.72 & 33.24 & 921.41 & 1104.90 & 25.83 & 93.18 \\
\hline 15.85 & 60.29 & 955.60 & 3631.27 & 15.12 & 95.39 \\
\hline 19.11 & 44.79 & 855.94 & 2006.14 & 21.26 & 111.25 \\
\hline 15.29 & 55.54 & 849.21 & 3084.69 & 17.00 & 111.18 \\
\hline $\begin{array}{c}\Sigma Y= \\
276.29\end{array}$ & $\begin{array}{c}\Sigma X_{1}= \\
484.11\end{array}$ & $\begin{array}{c}\Sigma X_{1} Y= \\
10546.51\end{array}$ & $\begin{array}{c}\Sigma X_{1}^{2}= \\
21044.90\end{array}$ & $\begin{array}{l}\Sigma \mathrm{Y}_{\mathrm{Cl}}= \\
261.10 \\
\end{array}$ & \\
\hline
\end{tabular}

Table 2 shows that as the moisture increases, the soil cohesion decreases. Increase in soil moisture content weakens soil molecular bond thereby decreasing the cohesive force of the soil particles. The angles of internal friction for Table 1 are $35.87^{\circ}, 37.73^{\circ}$, $35.79^{\circ}, 36.20^{\circ}$ and $43.86^{\circ}$. Table 3 shows that the linear relationship between shear stress and normal stress at moisture contents of $0 \%$, $5 \%, 10 \%, 15 \%$ and $20 \%$ respectively.

\section{Conclusion}

The study shows that the cone index and shear vane of fadama soils increased with depth and decreased with increase in moisture content. For this soil the critical moisture content was found to be $23.72 \%$. Moisture content beyond the critical level needs to be drained before cultivation is carried out.
Table 2. Statistical regression of field data of moisture content with shear vane

\begin{tabular}{|c|c|c|c|c|c|}
\hline \multirow{2}{*}{$\begin{array}{c}\text { Moisture } \\
\text { content } \\
(\%) Y\end{array}$} & \multicolumn{3}{|c|}{ Shear vane (kPa) } & \multirow{2}{*}{$\begin{array}{l}\text { Predicted } \\
\text { moisture } \\
\text { content } \\
\mathbf{Y}_{\mathrm{SV}}(\%)\end{array}$} & \multirow{2}{*}{$\begin{array}{l}\text { Efficiency } \\
\mathbf{Y} / \mathbf{Y}_{\text {Sv }} \times 100 \\
(\%)\end{array}$} \\
\hline & $\mathbf{X}_{2}$ & $\mathbf{X}_{2} \mathbf{Y}$ & $\mathbf{X}_{2}{ }^{2}$ & & \\
\hline 22.60 & 26.25 & 593.25 & 689.06 & 23.98 & 106.11 \\
\hline 24.84 & 26.50 & 658.26 & 702.25 & 23.94 & 96.38 \\
\hline 23.74 & 23.50 & 557.84 & 552.25 & 24.44 & 102.95 \\
\hline 18.03 & 24.25 & 437.23 & 588.06 & 24.32 & 134.89 \\
\hline 21.53 & 32.00 & 688.96 & 1024.00 & 23.02 & 106.92 \\
\hline 19.58 & 36.75 & 719.57 & 1350.56 & 22.22 & 113.48 \\
\hline 21.10 & 34.75 & 733.23 & 1207.56 & 22.56 & 106.92 \\
\hline 46.80 & 32.50 & 1521.00 & 1056.25 & 22.94 & 49.01 \\
\hline 27.72 & 37.50 & 1039.50 & 1406.25 & 22.10 & 79.73 \\
\hline 15.85 & 36.75 & 582.44 & 1350.56 & 22.22 & 140.19 \\
\hline 19.11 & 35.50 & 678.41 & 1260.25 & 22.43 & 117.37 \\
\hline 15.29 & 37.75 & 577.19 & 1425.06 & 22.06 & 144.28 \\
\hline $\begin{array}{c}\Sigma Y= \\
276.29\end{array}$ & $\begin{array}{l}\Sigma \mathrm{X}_{2} \mathrm{Y}= \\
8786.98\end{array}$ & $\begin{array}{c}\Sigma \mathrm{X}_{2} \mathrm{Y}= \\
8786.98\end{array}$ & & $\begin{array}{c}\Sigma X_{2}^{2}= \\
12612.11\end{array}$ & \\
\hline
\end{tabular}

Table 3. Relationship between shear stress and normal stress

\begin{tabular}{|c|c|c|c|c|c|}
\hline \multicolumn{5}{|c|}{ Shear stress $\tau(\mathrm{kPa})$} & \multirow{2}{*}{$\begin{array}{l}\text { Normal } \\
\text { stress } \sigma \\
(\mathrm{kPa})\end{array}$} \\
\hline $\begin{array}{c}\tau \\
(0 \% \text { m.c })\end{array}$ & $\begin{array}{c}\tau \\
(5 \% \text { m.c })\end{array}$ & $\begin{array}{c}\tau \\
(10 \% \text { m.c })\end{array}$ & $\begin{array}{c}\tau \\
(15 \% \text { m.c }\end{array}$ & $\begin{array}{c}\tau \\
(20 \% \text { m.c })\end{array}$ & \\
\hline 178.6 & 126.1 & 138.6 & 114.1 & 115.3 & 188.0 \\
\hline 267.6 & 292.7 & 191.6 & 225.8 & 216.6 & 324.3 \\
\hline 367.8 & 337.0 & 314.3 & 323.5 & 37.6 & 460.5 \\
\hline 474.2 & 456.4 & 388.1 & 423.6 & 478.5 & 596.8 \\
\hline
\end{tabular}

\section{References}

1. Tiner, R. 1999. A Wetland Sourcebook and Field Guide In: Search of Swampland, Rutgers (ed), University Press New Brunswick, NJ.

2. Mijindadi, N. B., Q. Umar and M. N. Tyem 1993. ADP Experience with Fadama Development: Achievements, Problems and Prospects. In: Irrigation Research Priorities for Nigeria, Nwa, E.U. and P. Pradhan (editors). Proceedings of a National Seminar organized by the International Irrigation Management Institute (IIMI), Kano and University of Ilorin, Ilorin. Pp 4450.

3. Gee-Clough D. and T. Wang, 1993. Deformation and Failure in Wet Clay Soil: Part 1, Stress-Strain Relationships. J. of Agric. Engng. Res. 54, 37-55.
4. Hanselman, D. P. Jr. and M. R. Noll 2002. Spatial Variation in Wetland Soil Properties as influenced by Hydrology and Elevation in a Coastal Wetland of Lake Ontario. Paper No. 66-32, Geological Society of America (GSA) abstracts with Programs.

5. Hanselman, D. P. Jr. and M. R. Noll, 2003. Meter Scale Variability of Soil Properties in a Lake Ontario Coastal Wetland, Paper No 75-15, Geological Society of America (GSA) abstracts with Programs, Vol. 35, No.6, p 160.

6. Reece, A. R., 1971. The shape of the form tractors, J. of Agric. Engng. 26(4): 20-24. 